\title{
As representações parentais em crianças institucionalizadas filhos de usuária de crack
}

\section{Parental representations in institutionalized children of crack user}

\section{Representaciones de los padres en niños institucionalizados hijos de usuario de crack}

\author{
Luciane Maria Both* \\ Universidade do Vale do Rio dos Sinos - UNISINOS, São Leopoldo, Rio Grande do \\ Sul, Brasil
}

\author{
Sílvia Pereira da Cruz Benetti** \\ Universidade do Vale do Rio dos Sinos - UNISINOS, São Leopoldo, Rio Grande do \\ Sul, Brasil
}

\begin{abstract}
RESUMO
O uso do crack pelos pais é o principal motivo de acolhimento institucional infantil e afeta as representações mentais das figuras parentais. Entretanto, são precários estudos com essa problemática. Assim, este estudo investigou as representações mentais de crianças institucionalizadas filhos de usuária de crack. Trata-se de uma pesquisa qualitativa com três crianças institucionalizadas da mesma família. Instrumentos utilizados: MacArthur Narrative Coding Manual (MSSB), Child Behavior Checklist (CBCL), desenho da família e investigada história familiar. Observaram-se comportamentos e emoções prejudiciais que indicam um ambiente desestruturado para 0 desenvolvimento mental das crianças. Destaca-se a negligência de cuidados e afetos, ocasionando representações mentais negativas. Verificou-se que as figuras de cuidado foram apresentadas como punitivas, disciplinadoras e ineficazes. Ressalta-se que a compreensão das representações parentais auxilia no entendimento das conflitivas infantis, planejamento da intervenção, mudança terapêutica e ações preventivas.
\end{abstract}

Palavras-chave: crack, acolhimento institucional, representação mental.

\section{ABSTRACT}

The use of crack by parents is the main reason of child residential care and affects the mental representations of parental figures; however, studies are precarious with this problem. This study investigated the mental representations of institutionalized children and crack user children. This is a qualitative research with three institutionalized children, of the same family. Instruments used: MacArthur Narrative Coding Manual (MSSB), Child Behavior Checklist (CBCL), family design and investigated family history. There were harmful behaviors and emotions that indicate an unstructured environment for the mental development of children. We highlight the neglect of care and affection, causing negative mental representations. It 
was found that care figures have been filed as punitive disciplinary and ineffective. It's emphasized that the understanding of parental representations contributes to the understanding of children's conflicting, intervention planning, changes in therapy and preventive actions.

Keywords: crack, residential care, mental representation.

\section{RESUMEN}

El consumo de crack por los padres es la razón principal del niño de atención residencial y afecta a las representaciones mentales de las figuras parentales; sin embargo, los estudios son precarias con este problema. Este estudio investigó las representaciones mentales de los niños institucionalizados hijos de usuaria de crack. Se trata de una investigación cualitativa con tres niños institucionalizados, de la misma familia. Instrumentos utilizados: MacArthur Narrative Coding Manual (MSSB), Child Behavior Checklist ( $\mathrm{CBCL})$, diseño de la familia y la historia familiar investigado. Hubo comportamientos dañinos y emociones que indican un entorno no estructurado para el desarrollo mental de los niños. Destacamos la falta de cuidado y afecto, haciendo representaciones mentales negativos. Se encontró que las cifras de atención se han presentado como punitiva disciplinaria e ineficaz. Se hace hincapié en que la comprensión de las representaciones de los padres contribuye a la comprensión del conflicto, la planificación de la intervención de los niños, los cambios en la terapia y acciones preventivas.

Palabras clave: crack, atención residencial, representación mental.

\section{Revisão Bibliográfica}

Abrigo é o termo criado na década de 1980 (Prada, Williams, Weber, \& 2007) para designar a instituição que acolhe e protege crianças e adolescentes em situação de risco pessoal e/ou risco social (Fante \& Cassab, 2007; Prada \& Weber, 2006). As causas de ingresso nessa instituição são multifatoriais: pobreza, desestruturação familiar (Azôr \& Vectore, 2008), casos de violência classificados como sexual, psicológica, física e negligência (Giacomello \& Melo, 2011; Mendes \& Sani, 2015; Souza, 2015), dependência química ou prisão dos pais ou responsáveis (Silva, 2004). Ou seja, situações de abandono ou de violação dos direitos (Brasil, 1999), cuja suspensão do poder familiar se dá por decisão judicial (Brasil, 2009) caracterizando tal medida como protetiva e excepcional de transição até que haja solução para o caso com retorno à família de origem ou encaminhamento à família substituta a partir da destituição do poder familiar (Brasil, 1999).

A lógica da exclusão referente aos abrigos está instituída na sociedade (Ferreira \& Bittencourt, 2009; Nascimento, Lacaz, Travassos, 2010) e o caráter asilar pode provocar dificuldades de relacionamento no convívio social futuros e tornar os jovens institucionalizados mais vulneráveis a doenças físicas ou psíquicas. Pois, no atendimento massificado e despersonalizado, não há formação de identidade ou sentimento de segurança emocional (Cavalcante, Silva, Magalhães, 2010), há estigma social pejorativo e 
depreciativo, relacionado à institucionalização (Siqueira \& Dell'aglio, 2006; Souza, 2015), carência afetiva, dificuldade para estabelecimento de vínculos, baixa autoestima, atrasos no desenvolvimento psicomotor, pouca familiaridade com rotinas familiares (Silva, Mello, Aquino, 2004), isolamento, comportamento agressivo, desenvolvimento cognitivo verbal inferior às crianças em meio familiar de vida (Pinhel, Torres, Maia, 2009), comportamentos rebelde, dificuldades escolares, enurese noturna e experiências sexuais precoces (Mendes \& Sani, 2015; Vectore \& Carvalho, 2008). Entretanto, esses autores consideram os comportamentos como a indisciplina, uma estratégia de sobrevivência no espaço institucional. Segundo Silva (2004), os dirigentes apontaram que o abrigo é a solução mais fácil, mas o que deveria ser feito é "tratar" o ambiente familiar "doente" (Vectore \& Carvalho, 2008), pois se sabe que os pais que negligenciam ou maltratam seus filhos possuem muitos outros problemas como doença mental, demais questões de saúde e histórias de violência doméstica (ICF International, 2009).

Segundo o Relatório da Infância e Juventude (2013), aproximadamente 29 mil crianças e adolescentes encontravam-se em acolhimento institucional no Brasil no ano de 2013, com as seguintes causas principais: pais ou responsáveis dependentes químicos/alcoolistas (81\%); negligência (81\%); dentre outras. Em especial nos abrigos residenciais estaduais de Porto Alegre (POA), há 521 acolhidos, com 136 devido a uso de substância psicoativas dos pais (FPE, 2014). E sobre o uso de drogas, em um panorama internacional, 8.3 milhões de crianças moravam com pelo menos um dos pais abusando de drogas ilícitas durante o ano de 2008 (ICF International, 2009).

Nesse sentido, pode-se destacar o aumento dos usuários de crack (Perrenoud \& Ribeiro, 2012), mencionada como a droga da morte (Alcioli Neto, 2014; Andrade, 2011). Cerca de 2 milhões de brasileiros já usou cocaína fumada (crack/merla e oxi) alguma vez na vida, um em cada cem adultos usou crack no último ano, representando 1 milhão de pessoas (INPAD, 2013) e segundo a Organização Mundial da Saúde (OMS) no Brasil, 3\% da população é usuária de crack (Camargo \& Martins, 2012), onde o uso predominante é na região Sul do país (Bordin, Fiflie, Laranjeira, 2010). Esta droga é uma substância recente, surgiu na década de 1980 nos Estados Unidos da América (EUA), chegando ao Brasil na década de 1990 (Kessler \& Pechansky, 2008; Perrenoud \& Ribeiro, 2012).

O crack é uma derivação da cocaína (Alves, Ribeiro, Castro, 2011; Botti, Costa, Henriques, 2011; INPAD, 2013), com o diferencial que é acrescida de bicabornato de sódio e substituiu o formato injetável pela via fumada; uma cocaína inalada (Bordin, Fiflie, Laranjeira, 2010; Espíndola et al., 2015; Kessler \& Pechansky, 2008;). É uma substância psicoativa euforizante (estimulante) (CNJ, 2011) e possui 
forma de "pedra" branca ou amarelada (Alcioli Neto, 2014; Camargo \& Martins, 2012). Ainda, comparado à cocaína, produz efeitos mais rápidos e intensos (Botti, Costa, Henriques, 2011; Ribeiro et al., 2012), pois atinge o sistema nervoso central em questão de segundos (Camargo \& Martins, 2012), além de que seus efeitos são mais prazerosos, cujos relatos de usuários descrevem uma "fissura" que os escraviza (Kessler \& Pechansky, 2008). Tais efeitos no corpo são diversos, há uma sensação de bem-estar e euforia, momento denominado high, porém os efeitos posteriores são disforia, irritabilidade, fadiga, impulsividade (Ribeiro et al., 2012), redução do apetite, ansiedade (Alves, Ribeiro, Castro, 2011; Bordin, Fiflie, Laranjeira, 2010), inquietação, agressividade, dor de cabeça, tonturas, desconfiança e sentimento de perseguição, depressão, insônia, convulsão (Bordin, Fiflie, Laranjeira, 2010; Espíndola et al., 2015), tal fase denominada crach, em que há esta redução no humor, para então voltar o desejo da droga, o "craving ou fissura" (Marques et al., 2012). Além disso, há outros sintomas físicos relacionados ao uso do crack: aumento da frequência cardíaca, tremores, espasmos musculares, entre outros (Alves, Ribeiro, Castro, 2011; Bordin, Fiflie, Laranjeira, 2010; Ribeiro et al., 2012). É preocupante a velocidade de deterioração mental, social e orgânica dos usuários (Kessler \& Pechansky, 2008). Porém são os efeitos positivos como aumento da autoestima, exaltação e efeito anestésico que encorajam a continuidade do uso da droga, causando dependência (Bordin, Fiflie, Laranjeira, 2010).

O seu tratamento é considerado difícil, exigindo uma abordagem multidisciplinar (Kessler \& Pechansky, 2008; Pettenon \& Diemen, 2010), com estratégias de prevenção de recaída, redução de danos, apoio a rede familiar para dar suporte ao usuário. Entretanto a rede pública não tem capacidade de suprir com toda a demanda (Espíndola et al., 2015; Kessler \& Pechansky, 2008). Há uma fragilidade das políticas públicas brasileiras, mencionando o despreparo das equipes e o estigma ao usuário de substância psicoativa quando este busca atendimento (Andrade, 2011; Barbosa, et al. 2015). O acesso a tratamento é mais difícil talvez em decorrência da ilegalidade da droga, ligada à criminalidade (Marques et al., 2012).

Há condições psiquiátricas associadas ao seu uso (Bordin, Fiflie, Laranjeira, 2010), como depressão e ansiedade (Marques et al., 2012), ou ainda é uma tentativa de manejar sintomas de comorbidades já existentes como é o caso de $76 \%$ dos casos dos EUA, cujas comorbidades mais comuns citadas são: transtornos afetivos (depressão, bipolaridade), transtorno de ansiedade, transtornos de personalidade (antissocial, Borderline, narcisista) (Bordin, Fiflie, Laranjeira, 2010). Além disso, esses usuários apresentam um comportamento mais violento (Bordin, Fiflie, Laranjeira, 2010; Pettenon, Diemen, 2010, CNJ 2011), tais 
comportamentos, delitos e prostituição, podem ser justificados pela necessidade de obtenção de dinheiro para sustentar o vício (CNJ, 2011).

Ainda, há dados indicando que nos anos de 2006 e 2007, 5,2\% das gestantes entre idades de 15 a 44 anos usaram drogas ilícitas (ICF International, 2009), bem como há dados de entrevistas realizadas nas maternidades dos hospitais públicos brasileiros, os quais apontam que, das mil adolescentes grávidas entrevistadas, 0,4\% fez uso de crack no último trimestre gestacional; isso ocasiona aumento da contração uterina com redução do aporte sanguíneo ao feto, deslocamento de placenta, trabalho de parto prematuro, lesões cerebrais (Moreira, Mitsuhiro, Ribeiro, 2012), má formação congênita, retardo do crescimento intrauterino (Bordin, Fiflie, Laranjeira, 2010) vasoconstrição, pois há alteração do transporte de substâncias pela placenta, aborto espontâneo dependendo da quantidade de uso e os órgãos mais afetados no feto são o cérebro, com morte dos neurônios, o pulmão cujos detritos são absorvidos pelo sangue e assim percorrem todo o corpo e afeta consideravelmente o fígado, que é responsável por limpar as impurezas do sangue (Camargo \& Martins, 2012).

No recém-nascido, esse uso de substância psicoativa durante a gestação gera algumas consequências, conforme a intensidade do uso que a mãe utilizou a droga: baixo peso, sudorese, convulsões, anomalias congênitas, comprometimento intelectual e cognitivo, principalmente retardo, (Moreira, Mitsuhiro, Ribeiro, 2012), irritabilidade, tremores (Bauer et al., 2005; Moreira, Mitsuhiro, Ribeiro, 2012), estão sempre alertas, choro frequente (Bauer et al., 2005), tais características referem-se a "síndrome de abstinência" neonatal, havendo sintomas típicos da falta da droga (Marques et al., 2012). A respeito da evolução dessas crianças, devido ao baixo peso ao nascer e não serem tanto tempo amamentados, há maiores chances de estarem abaixo da estatura média para a sua idade (Covington et al. 2002). Porém, em estudos na UFRGS com a médica Gabrielle Cunha sobre o efeito da droga durante a gravidez apontam que esses bebês não nascem dependentes dessa substância ou sofrem abstinência, apesar de poderem apresentar alterações químicas no cérebro, temporárias ou não, ou seja, há incertezas nos resultados (Camargo \& Martins, 2012).

Filhos de dependentes químicos apresentam riscos aumentados de desenvolverem algum transtorno psiquiátrico ou algum problema físico-emocional ou dificuldade escolar, dificuldade de atenção, irritabilidade, possibilidade de sofrer com estigma social (ICF International, 2009), comportamento delinquente, problemas de contato social (Payá \& Figlie, 2010), déficit cognitivo (Marques et al., 2012). Além de ter maiores chances de ser um futuro usuário (Pinho 
et al., 2012), cujo ambiente familiar torna-se modelo para o uso de drogas (Payá \& Figlie, 2010; Marques et al., 2012).

$\mathrm{Na}$ dinâmica familiar, o consumo modifica a interação, causa distanciamento entre os membros da família e modifica o comportamento dos filhos: comportamento antissocial, medo de agressão, insegurança (Pinho et al., 2012). Além disso seu uso pelos pais é causador de maus tratos e maus cuidados, (Bordin, Fiflie, Laranjeira, 2010; Mcarthur, Moore, Noble-Carr, 2010), abuso (Bordin, Fiflie, Laranjeira, 2010; Payá \& Figlie, 2010), ruptura da estrutura familiar, exposição a estresse, psicopatologia na criança, em especial transtorno de hiperatividade, de déficit de atenção e de conduta (Payá \& Figlie, 2010).

A família é a base da sociedade e é considerada a primeira forma de socialização (Fante \& Cassab, 2007; Mendes \& Sani, 2015; Siqueira \& Dell'aglio, 2006) e de interação (Bronfenbrenner, 1996) do indivíduo, bem como é a estrutura vital à humanização e espaço privilegiado para o desenvolvimento integral do jovem (Brasil, 2006). Os vínculos familiares são considerados uma condição primordial para o desenvolvimento psicossocial pleno (Ferreira \& Bittencourt, 2009), cuja relação mãe-criança tem uma importância fundamental e as separações precoces podem ser deletérias para o desenvolvimento das crianças, pois a perda dos cuidados maternos no início da infância pode provocar sérias alterações na formação da personalidade infantil, além da angústia de separação presente (Bowlby, 2006). Dessa forma, as crianças institucionalizadas que sofrem essa ruptura podem desenvolver um quadro psicotizante devido à falta de referência materna e familiar (Perreira, 2004).

Segundo Bowlby (1984), a saúde mental tem como base os cuidados parentais recebidos nos primeiros anos de vida. $\mathrm{Na}$ teoria winnicottiana o desenvolvimento emocional primitivo de um indivíduo depende da unidade mãe-bebê (Winnicott, 1988), em que o bebê depende da disponibilidade de um adulto genuinamente preocupado com os seus cuidados, isto é, sensível às necessidades da criança (Winnicott, 2000).

Diante do contexto familiar, os filhos internalizam essas relações que se tornam a base de como a criança interpreta a realidade e interage com ela; para isso denomina-se representação mental, que funcionam como um mapa interno que guia o comportamento dos indivíduos (Custódio \& Cruz, 2008). Essas representações mentais são reflexos do modelo precoce de vinculação com as figuras cuidadoras, cujo modelo determinará o padrão relacional futuro, influenciando na organização dos afetos, da cognição e do comportamento e consideravelmente na saúde mental das crianças (Pinhel, Torres, Maia, 2009). O modelo representacional das figuras de vinculação terá uma probabilidade maior de possuir respostas 
mais adaptativas a situações adversas quando comparado às crianças com pais indisponíveis e abusivos (Bowlby, 1981).

Dessa forma, as crianças em realidade de acolhimento desenvolvem um modelo inseguro de vinculação pela falta de referência; tal padrão de vinculação possui temas marcados por abandono, punição, negligência, inversão de relações familiares, algumas delas com conteúdos fortemente sexualizados e possuem diversos problemas comportamentais, tais como: isolamento, comportamento agressivo, desenvolvimento cognitivo verbal inferior às crianças em meio familiar de vida normal. Tais atitudes refletem as representações mentais negativas (Pinhel, Torres, Maia, 2009). De igual modo, evidencia-se que pais que abusam de drogas não irão estabelecer um relacionamento emocional e modelo parental seguro com seus filhos.

Entretanto, essas repercussões negativas decorrentes da institucionalização podem ser minimizadas se tais crianças receberem cuidados maternos adequados às suas necessidades, próximos aos que deveriam ser supridos pela figura materna; isso implica também na capacidade de resiliência de cada criança (Bowlby, 1981). A instituição de acolhimento pode tanto ser um local pior, ou melhor, para criança quando comparado ao ambiente familiar anterior, cujos efeitos da separação podem ser mínimos se haver no novo ambiente cuidados maternais de uma mãe substituta e a presença de objetos familiares à criança (Siqueira \& Dell'aglio, 2006). Tais autoras afirmam que esse ambiente pode configurar-se como sendo um espaço para o desenvolvimento saudável de crianças e adolescente em que se torna pertinente considerar que esta instituição faz parte da rede de apoio social e afetivo que fornece recursos para 0 enfrentamento de eventos negativos, modelos identificatórios positivos, proteção, segurança.

Desse modo, pode-se constatar a necessidade de pesquisa abordando as representações parentais no contexto institucional dos abrigos com filhos de usuárias de crack, visto a escassez de trabalhos brasileiros dessa natureza e a grande incidência de droga. Assim, objetiva-se compreender e refletir sobre as representações das figuras parentais em crianças em situação de acolhimento institucional oriundas de um meio familiar com pais usuários de crack; problematizar as consequências que 0 acolhimento gera nessas representações parentais e os efeitos da droga nessas representações desses jovens, para que possam ser desenvolvidas ações terapêuticas e preventivas mais eficazes a essas crianças. Também, serão considerados alguns atravessamentos implicados nesse processo, como estrutura familiar, idade, tempo de institucionalização, aspectos biopsicossociais do uso do crack e atravessamentos das políticas públicas. 


\section{Metodologia}

Este estudo consiste em uma pesquisa qualitativa, visando explorar os processos subjetivos no ambiente natural do participante, ou seja, é uma pesquisa interpretativa (Creswell, 2010). Ainda, não se pode deixar de se considerar que em uma pesquisa qualitativa há uma maior manifestação da subjetividade do pesquisador (Pereira, 1999), em que o pesquisador ocupa um papel fundamental nesse tipo de pesquisa (Creswell, 2010).

Participaram da pesquisa três crianças, ambos os irmãos: Bruna (09 anos), Gabriela (06 anos) e Gabriel (03 anos) ${ }^{1}$ que se encontravam em situação de acolhimento em instituições de proteção especial mantida pelo governo. A seleção destes participantes ocorreu a partir de critérios de inclusão definidos em faixa etária (entre três e doze anos), tempo de acolhimento (mínimo de cinco meses) e com mãe usuária de crack. A permissão da participação das crianças na pesquisa correu através da assinatura do responsável legal no Termo de Consentimento Livre e Esclarecido (TCLE).

A coleta de dados se deu na sala de atendimento psicológico da instituição com cada criança individualmente. A pesquisadora explicou que tratava-se de uma pesquisa e convidou para a participação voluntária. Então iniciou-se com a realização do Desenho da Família e em seguida foi aplicado o MacArthur Narrative Coding Manual (MSSB). Nessas histórias foi utilizado a família terapêutica para facilitar a dramatização. $O$ atendimento foi gravado e depois transcrito para a análise dos dados. Quanto ao Child Behavior Checklist $(\mathrm{CBCL})$, foi selecionado o agente educador do abrigo residencial que mais possuía vínculo com a criança para responder 0 instrumento.

A partir da consulta ao prontuário e processo judicial de cada criança participante, é possível abranger dados referentes à história de vida, dados sociodemográficos e demais informações de cunho psicológico presentes. Além disso, o material gráfico auxilia na orientação de hipóteses interpretativas, que combinadas com a história clínica, é possível compreender melhor o sujeito (Buck, 2009) e perceber alguns aspectos das relações, dos conflitos e das representações dos vínculos familiares de cada criança, pois o desenho da família permite a criança projetar do seu inconsciente as tendências recalcadas (Corman, 1979). Também foram utilizados para a coleta de dados os instrumentos: MSSB, CBCL.

\section{MacArthur story stem battery (MSSB)}

É um método composto de 15 narrativas utilizadas para investigar o desenvolvimento social, emocional e moral infantil, que consiste na 
exposição inicial de um enredo. Em seguida a criança continua tal narrativa, em que houve a dramatização. Entretanto, duas das histórias não são avaliadas, pois tem o objetivo de introduzir e finalizar a aplicação (Emde, Wolf, Oppenheim, 2003). Nas demais, os itens são pontuados por codificações numéricas que possuem variação de 0 a 10 pontos, segundo o MacArthur Narrative Coding Manual (Robinson et al., 2007). Também, para a dramatização das narrativas foi utilizado os bonecos da Família Terapêutica com o intuito de facilitar a expressão das crianças.

\section{Child Behavior Checklist (CBCL)}

O CBCL é um Inventário de Comportamentos na Infância e Adolescência utilizado para investigar manifestações clínicas na infância e adolescência (Achenbach, 1991). Foi criado nos Estados Unidos e validado no Brasil por Bordin, Mari e Caeiro (1995). Ele mede o grau de competência social e os problemas comportamentais de uma criança ou adolescente de acordo com a percepção de seus pais ou cuidadores (Achenbach, 1991). É composto de 138 itens e ao final, as respostas ao CBCL classificam a criança como Clínica ou NãoClínica para Competência Social e Problemas Totais de Comportamento. Entretanto, essa classificação não representa um diagnóstico da criança, ela somente aponta a categoria na qual a criança melhor é classificada, de acordo com o instrumento (Borsa \& Nunes, 2008).

\section{Resultados}

A codificação das narrativas dos três participantes foi realizada a partir do MacArthur Narrative Coding Manual (Robisnson et al., 2007). As narrativas não estão transcritas em sua totalidade de extensão, assim como o comportamento não verbal não está aqui referido, embora tenham sido considerados nas análises.

Durante a aplicação do MSSB, Bruna mostrou-se tranquila e dedicada na construção das narrativas. Comunicava-se muito verbalmente, apesar de utilizar-se dos bonecos e os enredos restringiam-se a proposta apresentada inicialmente em cada história. Houveram os seguintes resultados: houve destaque na capacidade de resolução de conflitos (História 05: "aí ele ficou brabo, fica chorando. Aí ele pediu para a mãe dele contar uma história para ele") e complacência que a mesma apresentava em relação às figuras de autoridade. Demonstrou situações de culpa (História 08: "a mãe dela deixou ela de castigo, aí ela nunca mais fez isso"). Na maioria das narrativas ficaram evidenciados conteúdos positivos nos finais das histórias, 
com sinais de esperança, às vezes parecendo incoerentes com a frase "e viveram felizes para sempre" (sic). As figuras parentais foram retratadas como cuidadoras em algumas narrativas, porém não foram representadas como afetuosas ou protetivas. Pelo contrário, em algumas apresentaram pais disciplinadores e ineficazes, dando castigos como forma de punição e não cumprindo adequadamente a função parental. Bruna apresentou material traumático invasivo em três narrativas e fuga de assuntos dolorosos em cinco delas, em cinco histórias ela brincou fora do assunto e utilizou-se da negação como mecanismo de defesa (História 07: as chaves foram logo entregues e o desenrolar da história se focou em brincadeiras entre pai e filha). Houve predominância de angústia e de comportamento ansioso, cuja resolução do conflito proposto na história se dava rapidamente. $\mathrm{Na}$ avaliação das manifestações clínicas da infância conforme o CBCL (Achenbach, 1991), Bruna obteve resultado um nível limítrofe (Borderline) de funcionamento para sintomas de externalização associados ao comportamento agressivo e de conduta e sintomas internalizantes apresentando problemas de ordem afetiva com ansiedade e reclamações somáticas.

No MSSB a Gabriela estava motivada para participar da aplicação, porém em alguns momentos, demonstrou estar mais frágil emocionalmente, brincando fora do assunto e desviando do tema inicial da correspondente narrativa, mas que revelavam conteúdos pesados que provavelmente se assemelhem com experiências anteriores. Ela utilizou a Família Terapêutica intensamente para expressar-se, principalmente demonstrando agressivamente cenas de violência entre os pares e conteúdos sexualizados. Houve relevância apenas para a existência de censura em três narrativas (História 09 com situação de agressão e a fala "o que está acontecendo aqui?"), assim como na maioria das narrativas houve afeto presente, com presença de carícias entre os personagens. Houve elevada pontuação na existência de agressão (Histórias 04, 06 e 12 com morte de algum personagem; outras sete narrativas com agressão, sendo que em duas a própria criança agredindo fisicamente os pais), também houve agravamento do conflito interpessoal em sete narrativas, como cenas de desmaios e choros e demais agressões; bem como existência de respostas atípicas predominantemente e atividade sexualiazada em seis narrativas, havendo cenas de beijos entre irmãos na história $01 \mathrm{e}$ 09, beijos entre os pais na história 03 e 08 e na história 12 há cenas de sexo entre os pais. As figuras parentais foram retratadas em predominância como ineficazes, com dificuldades dos pais em ajudar a criança, e de rejeição, em que os pais afastam-se da criança, preocupados com apenas seus interesses. Gabriela manifestou sentimentos de angústia e tristeza (História 01: "aí a mãe dele deixou ele de castigo no quarto (...) ele ficou muito triste, aí a mãe dele falou: vai pro quarto agora, vai pro quarto agora"). Suas narrativas 
foram em sua maioria incoerentes a proposta inicial da narrativa, havendo conflitos alterados e manipulação de alguns fatos, geralmente agravando a situação. Houve material traumático presente em praticamente todas as narrativas, evidenciados pelo número de cenas de violência como uma tentativa de fuga de algum assunto doloroso, bem como em cinco histórias houve identificação da menina com o agressor. Conforme o CBCL (Achenbach, 1991), Gabriela obteve indicador Clínico para sintomas de externalização associado a problemas de déficit de atenção e comportamento agressivo e problemas na conduta.

E o Gabriel estava inicialmente interessado na atividade do MSSB, mas algumas vezes demonstrou resistência, provavelmente por abordar conteúdos que para ele fossem mais difíceis. Durante todo o momento ele pedia constantemente a participação da pesquisadora na produção e interação da narrativa, utilizando-se muito dos bonecos para as dramatizações. Seu discurso, entretanto, era confuso e sempre que questionado para clarificar tal afirmação, ele modificava o que ele havia proposto. Houve complacência em relação às figuras de autoridade. Sobre a agressão desregulada houve agressão em cinco histórias, apresentando morte de algum personagem em quatro delas (História 06: "ele empurrou e a irmãzinha morreu"), também houve agravamento do conflito na maioria das narrativas com incremento de animais ferozes que matam os personagens e demais fantasias. Apareceram nas histórias 01 e 04 carícias e beijos entre os personagens. Em cinco narrativas houve a representação de pais cuidadores (História 02: "o pai bota ele na cama"; História 08: "aí a mamãe foi levar ele no médico"), punitivos e disciplinadores em três narrativas (História 13: "botaram ela de castigo"), de rejeição, em que a criança é deixada sozinha e ineficazes em três histórias cujos pais não ajudam quando necessário. Na maioria das narrativas houve a presença de comportamento ansioso diante alguma proposta que despertasse situações conflitivas e sentimentos dolorosos, cujos momentos eram enriquecidos com personagens fantasiosas e enredos atípicos demasiados que em muitos momentos influenciaram na coerência dos relatos. E conforme o CBCL (Achenbach, 1991), Gabriel obteve resultado Clínico para sintomas de externalização associados aos problemas de déficit de atenção e comportamento agressivo e sintomas internalizantes apresentando problemas de ordem afetiva com sintomas de ansiedade e depressão.

A avaliação dos desenhos representacionais foi baseada tanto na técnica projetiva de desenho com o Teste H-T-P: casa-árvore-pessoa (HTP) (Buck, 2009), como no "O Teste do Desenho da Família" (Corman, 1979) para levantar as hipóteses interpretativas de cada um dos participantes. A criança, na linguagem dos desenhos, passa por diferentes estágios conforme a fase de desenvolvimento que a 
criança se encontra, mas que expressam sua vida e sua história espontaneamente e tais símbolos são considerados uma forma de comunicação (Rabello, 2013). Dessa forma, levou-se em conta a idade dos participantes, pois o Gabriel, por exemplo, não possui uma motricidade fina desenvolvida. É comum crianças abaixo de cinco anos realizar desenhos assimétricos e desenhos deformados, assim como crianças até dez anos em que são comuns figuras humanas incompletas (Capisano, 2010); entretanto permaneceu-se com a utilização dessa técnica pelo fato da criança poder projetar seus sentimentos e representações; podendo-se reforçar questões que foram observadas nos outros instrumentos. Destaca-se a existência de sentimentos de insegurança, ansiedade e agressividade presentes nos desenhos, talvez devido ao ambiente restrito em que a descarga pulsional é uma forma de reequilibrar o mundo interno. Ainda, há sentimentos de depreciação, que isso representa segundo Buck (2009) desejo de desaparecimento ou situação difícil entre os membros. Também, a imaturidade é evidente nas representações das formas humanas, cujas formas mecanizadas transcendem as limitações gráficas referentes a pouca idade.

\section{História Familiar}

A família Pires compõe-se de nove filhos, os quais são frutos de envolvimento da mãe com vários companheiros, conforme genograma abaixo (Figura 1). É oriunda da periferia da capital. Os/as filhos/as mais velhos/as foram entregues informalmente para outras famílias; a mãe e o atual companheiro apelavam para a mendicância e prostituição das filhas mais velhas. Esse companheiro está junto com ela há anos e é o pai de Gabriela, Gabriel e José Gabriel. No processo judicial, consta que a família é acompanhada pelo Centro de Referência Especializado de Assistência Social (CREAS), cujo serviço afirma que o ambiente familiar era de extrema negligência, com uso e tráfico de droga envolvendo até membros da família extensa, porém não havia adesão a nenhuma proposta de auxílio. A mãe vendia tudo o que conseguia e encontrava para comprar pedra de crack, que fumava na frente das crianças. Diante de todo esse contexto negligente, Bruna, Gabriela e Gabriel, devido à denúncia ao Conselho Tutelar, foram encaminhados a viver em abrigo institucional; assim como João Gabriel que estava institucionalizado desde o seu nascimento. As moças mais velhas já estavam vivendo com os seus namorados em boa situação, não mais expostas à negligência materna. Contudo, nesta pesquisa, o foco se limitará à Bruna, Gabriela e Gabriel. 
Figura 1: Genograma da Família ${ }^{2}$

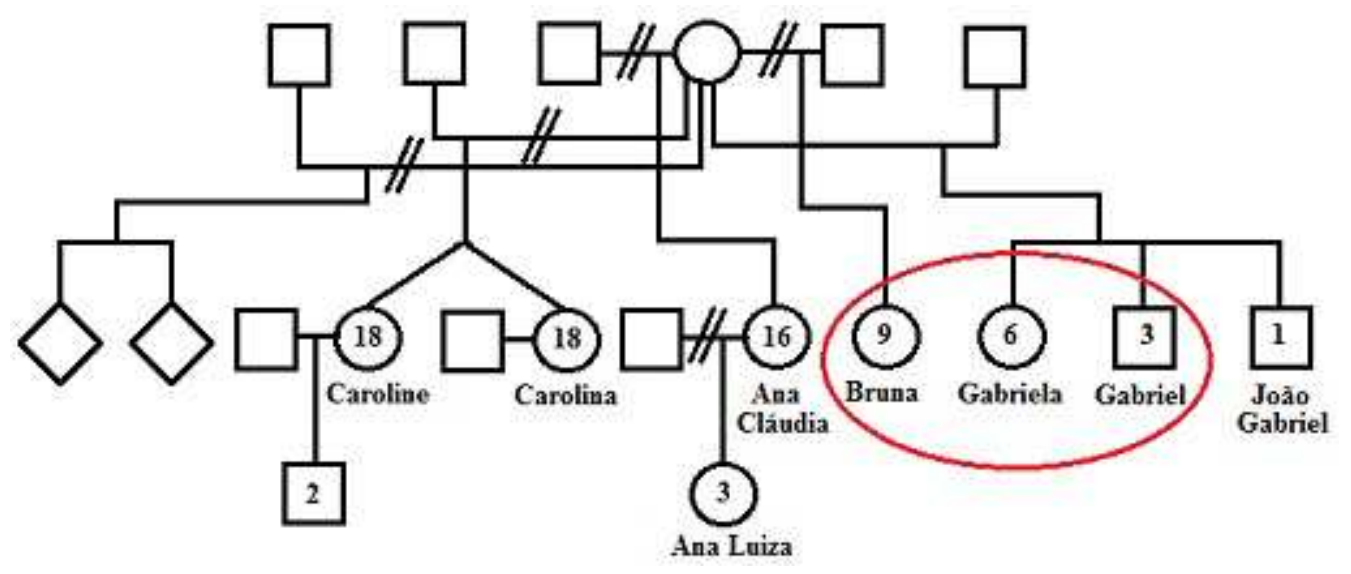

A mãe, durante a gestação de ambos os três filhos e do João Gabriel, fez uso de drogas ilícitas, supostamente crack, tanto que no caso de Bruna a mãe nem lembrava onde o parto foi feito para que se possa solicitar a declaração de Nascido Vivo, em 2013 a mãe estava presa por ser pega com pedras. As três adolescentes mais velhas prostituiam-se na rua, às vezes levando Bruna junto ou deixando-a cuidando dos irmãos menores em casa. Em decorrência de denúncia de vizinhos preocupados com as crianças, os quais alegaram por telefone que: "Crianças mal cuidadas pela mãe que é drogada, dorme até meio dia. As crianças estão com feridas, sujas, passam mendigando pela vizinhança". "Crianças passam fome" ${ }^{3}$, o Estado, por meio de Mandado de Busca e Apreensão, acolheu, em outubro de 2011, Bruna, Gabriela e Gabriel em um abrigo residencial e Ana Luiza, filha de Ana Cláudia, em outro. Na nova vida institucionalizada, houve algumas mudanças para Bruna, Gabriela e Gabriel, descritas a seguir.

Bruna, logo que chegou ao abrigo, queria cuidar dos irmãos do seu jeito, em função de ter feito isso no passado. Porém aprendeu seu novo papel, deixando tal tarefa aos agentes educadores. Ainda não possuía certidão de nascimento, mas mesmo assim começou a frequentar a escola. Foi alfabetizada e recebeu muitos elogios da professora no ano 2013, quando obteve aprovação para o $3^{\circ}$ ano do Ensino Fundamental. Ademais, ajudava nas tarefas domésticas do abrigo e era uma menina bastante dedicada às suas atividades, mas por vezes contestava solicitações dos agentes educadores e insinuava-se para os meninos mais velhos, usando roupas curtas e provocativas ou também dançando funk.

Gabriela começou a frequentar a escola, porém não conseguiu alfabetizar-se ainda, sendo reprovada no ano de 2013 e havendo a solicitação de atendimento psicopedagógico devido às dificuldades que enfrentava na escola. Há suspeita de defasagem no seu desenvolvimento cognitivo ou algum problema neurológico. No abrigo 
era chamada, às vezes, de "pimentinha" já que possuía um comportamento agitado. Tem diagnóstico de Transtorno de Déficit de Atenção e Hiperatividade (TDAH) realizado pelo neurologista e fez uso do medicamento Ritalina desde julho de 2013 aproximadamente, o que contribuiu na maior fixação da atenção em atividades rotineiras. No entanto, muito de sua sintomatologia decorre de conflitos emocionais não simbolizados, canalizados na ação. Ela apresentava um comportamento sexualizado em diversos momentos, muitas vezes sendo flagrada sem roupa junto com meninos da sua idade dentro do abrigo ou realizando brincadeiras com cunho sexual evidente.

Gabriel passava o dia na creche; era um menino bastante agitado, mas sociável, já estava começando a ficar mais independente, fazendo diversas atividades sozinho, mas frequentemente não obedecia as restrições dos funcionários, necessitando desses uma conduta bastante continente. Tinha dificuldades de expressar em palavras seus sentimentos ou de simbolizar nas brincadeiras, extravasando a ansiedade no ato, com expressão de agressividade.

Os pais continuavam a visitá-los nos finais de semana no próprio abrigo. Porém, por decisão da equipe técnica, a visita é sempre assistida, pois frequentemente havia desentendimentos entre os funcionários do abrigo e os pais. Os pais não queriam cumprir o combinado; invadiam a casa, entrando nos quartos, discutiam na frente de todos os jovens da casa, desrespeitavam todos. Os três filhos ficavam bastante agitados depois da visita dos pais. E ainda, Bruna necessitava ficar separada no quarto devido à suspeita de abuso do padrasto, denunciada e relatada pela própria menina. Nessa revelação ela disse que não houve penetração, porém reafirmou que era exposta a cenas de cunho sexuais inadequadas à sua idade quando acompanhava as irmãs. Ainda, em outro momento, Bruna revelou que este padrasto, quando a mãe não estava presente em casa, agredia a menina em virtude dela não ser sua filha; dessa forma, segundo ela, permaneceu durante um tempo vivendo com a sua avó.

Todos estavam em atendimento psicológico individual. Além disso, Gabriel e Gabriela realizaram no final do ano de 2013 uma avaliação neuropsicológica. Durante o ano de 2012 e 2013, os três participaram de um Grupo de Contos de cunho profilático, disponibilizado pela equipe de psicologia da instituição aos acolhidos, cujo objetivo era preventivo.

\section{Discussão}

O acolhimento institucional fragiliza os vínculos familiares, bem como o uso de drogas presentes na dinâmica familiar são marcantes na 
vida das crianças. Principalmente se o uso da droga é feito pela figura materna, que prejudica consideravelmente a relação mãe-bebê, a qual, por sua vez, afeta as representações mentais e estrutura de self da criança, podendo ocasionar diversos comportamentos e emoções disfuncionais. Nesse sentido, há uma associação entre modelos representacionais negativos e sequela psicológica, desse modo, a maneira como a criança internaliza tais representações, influenciam na maneira como ela se relaciona com o ambiente e como interpreta a realidade (Custódio \& Cruz, 2008).

Nos participantes desse estudo, observou-se que há comportamentos e emoções considerados prejudiciais. Por exemplo, na verificação dos dados do $\mathrm{CBCL}$, Bruna apresentou um nível limítrofe (Borderline) de funcionamento para sintomas de externalização e internalização, Gabriela com avaliação Clínica para sintomas de externalização e Gabriel também com avaliação Clínica para sintomas de externalização, além dos sintomas de internalização. Já no desenho representacional da família, esses mesmos sintomas de externalização aparecem pela agressividade e os sintomas de internalização na presença de sentimentos de insegurança, ansiedade e imaturidade. Entretanto, o que se destaca nos desenhos são os sentimentos de depreciação, que devido ao histórico dessas crianças compreende-se que determinadas situações são difíceis de abordar, dessa forma utilizam-se das estratégias de evitação e códigos de dissociação como observado no MSSB.

Tais resultados associados ao desenho representacional da família, às narrativas do MSSB e à história familiar, são indicativos de um ambiente desestruturado para o desenvolvimento mental das crianças. Observa-se que anteriormente ao acolhimento prevaleceu a negligência de cuidados e afetos, ocasionando representações mentais negativas, insegurança, e comportamentos agressivos e fantasiosos como forma de descarga e fuga da realidade. Posteriormente no abrigo, também devido à precariedade de alguns cuidados e condições, tais representações ainda permanecem.

O comportamento agitado reflete toda essa problemática, em que brincadeiras agressivas com os bonecos, por exemplo, demonstram uma descarga pulsional, cuja agressividade prevalece devido à ansiedade ser demasiada. Há necessidade de descarga, pois não conseguem externalizar verbalmente o latente. Também se pode hipotetizar que o comportamento agressivo é resultante da separação que sofreram ou do efeito do crack ainda no período intrauterino, em que ocasionou algumas sequelas biológicas.

Durante a coleta de dados, pode-se perceber que essa escuta às crianças foi um espaço terapêutico que de certa forma aliviou seu sofrimento. Em uma visão sobre as narrativas de maneira geral podese notar que há aspectos positivos presentes nos enredos e representações, o que sugere que tal momento foi auxiliar à 
revivência de alguns conflitos, dando ênfase a importância da atenção concedida aos participantes com interesse do terapeuta nas suas produções. Assim como, segundo Souza e Cruz (2010) as crianças contando histórias podem explorar diversas possibilidades e dar significações às suas experiências, às vezes utilizando a história como recurso para imaginar a forma como desejam ser a realidade.

A partir das narrativas com bonecos da Família Terapêutica e expressão no desenho representacional da família, foi possível oportunizar a livre expressão das crianças. O brincar para a criança é como a associação livre para o adulto (Bleichmar \& Bleichmar, 1992). Também é uma expressão de saúde capaz de recuperar a capacidade de movimento interno de forma criativa (re)constituindo aspectos do seu self, recriando sua própria realidade e história, ou seja, seria um meio transicional normal para a criança superar a separação de sua mãe, objeto de amor (Winnicott, 1975).

A avaliação das narrativas infantis do MSSB demonstra, nos três irmãos, material traumático invasivo e utilizam-se de defesas como a negação, evitando tocarem nos assuntos diretamente. Por exemplo, mesmo que as narrativas não tratassem de conteúdo sexualizado de forma expressiva, manifestaram-se nas narrativas momentos de afeto exacerbado tanto entre irmãos como entre figuras parentais. Há grande suspeita de abuso sexual, principalmente em Gabriela, pois o comportamento sexualizado é mais intenso; isso remete a hipótese de abuso sexual ou exposição de comportamentos impróprios à idade deles quando viviam com a mãe. Além disso, todos esses fatos demonstram que consideravelmente o ambiente em que estavam desenvolvendo-se não estava sendo adequado às suas necessidades. Complementar a isso, foram predominantes nos enredos das narrativas, representações parentais punitivas e ineficazes, caracterizando-se como figuras negativas; apesar de haverem presentes alguns aspectos positivos, mas que evidenciaram pouca afetividade.

Chamou a atenção principalmente da Bruna, o "viveram felizes para sempre", desfecho comum aos Contos de Fadas, apesar das dificuldades que os heróis tiveram que superar. Os Contos de Fadas são também uma dose de otimismo (Corso \& Corso, 2006). Esse final, "viveram felizes para sempre", demonstra à criança que a felicidade é possível, mesmo com todas as dificuldades vivenciadas pelos personagens, isto é, alude à esperança.

Esses resultados dessa pesquisa são semelhantes a alguns estudos já apresentados. Segundo Custódio e Cruz (2008), a qualidade de interação entre filhos e pais são associadas às representações de figuras parentais, que no caso com uma vinculação pobre, há a representação parental negativa. Esses elementos de evitação revelam que as crianças estão em sofrimento e não conseguem suportar os temas e sentimentos conflitantes, que dessa forma, 
fogem do assunto como tentativa de não entrar em contato com essa realidade, por exemplo, quando brincam fora do assunto ou fantasiam. Tais dissociações são comuns em crianças maltratadas, os quais atribuem que quanto maior os fatores de risco e dificuldades no relacionamento parental, maior será o uso dessas estratégias de esquiva (Grych, Wachmuth-Schlaefer, Klockow, 2002). Na maioria das situações, exceto Bruna que em alguns momentos apresentou maior capacidade de resolução de conflitos, as crianças se retrataram incompetentes frente ao conflito, apresentando muita ansiedade diante situações conflitivas.

Souza e Cruz (2010) desenvolveram duas hipóteses explicativas para a compreensão das narrativas do MSSB: hipótese representacional que se manifesta em crianças maltratadas, cujos personagens são colocados por elas em situações de conflito e tensão emocional, podendo haver episódio com ela sendo vítima de maltrato, reproduzindo a própria dinâmica familiar nas dramatizações; hipótese de regulação emocional em que as crianças modificam ou evitam representar determinados comportamentos com os personagens nos enredos das suas narrativas, ou seja, desviam do confronto e sustentam um mecanismo de regulação emocional. Dessa forma, identifica-se no presente estudo o uso das duas hipóteses; nas narrativas da Gabriela e Gabriel, há predominância da hipótese representacional, porém há desvio do conflito inicial e quando há o questionamento da situação, eles não conseguem verbalizar. Pelo contrário, Bruna possui predomínio da hipótese de regulação emocional. Talvez isso seja também influência da idade dos participantes, pois se observa principalmente em Gabriel maior fantasia no enredo.

Nesse trabalho prevalecem no aspecto temático das narrativas das crianças, conflitos associados à punição e negação, além de que nas próprias representações gráficas, sentimentos de insegurança, ansiedade, retraimento e impulsividade são predominantes, o que também sugere que a constituição de sujeito não corresponde a um sujeito saudável. No $\mathrm{CBCL}$, isso é exposto por um sujeito com ego desorganizado. Revela-se que tais crianças são vítimas de uma sociedade, possuem diversas dificuldades a serem trabalhadas. Uma das dificuldades que se pode encontrar no presente estudo é a possiblidade de discriminação das consequências da institucionalização e do uso do crack. Pois ambos possuem efeitos na constituição de sujeitos e são decorrentes da inexistência de um ambiente saudável.

Os três participantes, no geral, apresentaram problemas de ordem afetiva, comportamental e social, o que revelam o quanto estão vulneráveis diante todo contexto. Possivelmente com um entendimento melhor sobre suas representações mentais, será viável ofertar um trabalho mais qualificado às necessidades dessas crianças. 
Essas crianças precisam reconstruir tais experiências negativas que vivenciaram e essa responsabilidade é tanto dos profissionais da saúde, como da sociedade, necessitando maiores recursos e assistência adequada a essas famílias. É necessário oportunizar formas de apoio e cuidado, como: espaços de escuta para as crianças, estrutura física e afetiva adequada para o desenvolvimento adequado de crianças, figuras de referência fixas para as crianças que cumpram com as funções maternas, orientação aos funcionários dos abrigos, assistência social e psicológica para as famílias, desenvolver e implantar políticas públicas que apoiem essas famílias e oportunizem melhores condições de cuidado preventivo em período anterior ao encaminhamento de institucionalização. Tais atitudes certamente minimizariam, e até mesmo previne os impactos negativos da institucionalização, do uso do crack e da vulnerabilidade social no desenvolvimento das crianças.

Desse modo, considera-se o acolhimento institucional como uma consequência social, como o aumento do consumo de drogas, no caso refere-se ao crack, em que as vítimas de toda essa dinâmica são as crianças. Diante de tudo isso, há uma fragilização da estrutura de self devido ao ambiente desestruturado e inadequado, e como consequência ainda há representações das figuras parentais negativas. $\mathrm{E}$ tais representações influenciam na interpretação da realidade e no comportamento e relacionamento social desses jovens, que se reforça que se configurado de forma negativa, pode ser causa de mais problemas sociais. Assim, entende-se que 0 atendimento adequado e a oportunidade de revivência dessas experiências negativas podem trazer benefícios tanto à criança, como à sociedade de maneira geral.

\section{Considerações Finais}

A proposta desse estudo foi de investigar as representações parentais em crianças institucionalizadas filhas de usuárias de crack. Entretanto, as representações mentais referem-se a um fenômeno complexo, principalmente quando ligado a situações de vulnerabilidade em diferentes aspectos: emocional, social, financeiro. Dessa forma é necessário considerar todos os fatores de implicação presentes. São escassos estudos que investiguem as representações mentais dos pais quando há a influência direta do uso do crack no cuidado dos filhos, o que é contraditório à realidade, já que está cada vez mais comum esse tipo de situação. Nos resultados foram evidenciadas questões relevantes observadas como limitadoras e negativas em relação às figuras parentais, que afetaram o desenvolvimento saudável dessas crianças. 
Nesses locais de acolhimento institucional evidencia-se 0 encaminhamento de crianças nesse contexto. Salienta-se que o acolhimento institucional é uma consequência de todo um sistema social perverso, cujo estigma torna-se evidente e prejudicial. Entretanto, essa nova condição de moradia à essas crianças institucionalizadas possuem aspectos benéficos protetivos se 0 ambiente for adequado às necessidades da criança e com pessoas de referência que possibilitem o desenvolvimento saudável. Porém, destaca-se a complexidade que é para uma instituição substituir as funções parentais. Dessa forma, é necessário investir em estratégias que possam beneficiar cada vez mais este público, como oferecer espaços terapêuticos que considerem as características do desenvolvimento da criança para o resgate de possibilidades de identificação mais sadias e fortalecimento de recursos internos das crianças. Nas crianças participantes percebeu-se que essas foram convocadas a lidar com situações estressantes prematuramente. Dessa forma há significativa depreciação, ansiedade e negação presentes advindas de uma tentativa de manter uma organização, ou seja, um movimento de saúde, pois apesar de todo histórico, tais crianças não psicotizaram.

Certamente esta pesquisa não saturou o conhecimento sobre o tema, sugerindo-se maior investimento em estudos com populações usuárias de crack, já que é um contexto cada vez mais comum na sociedade. Aponta-se que as limitações do estudo se referem a uma amostra com pouca representatividade. Assim como foram utilizados instrumentos não validados à população brasileira, o que pode ter comprometido a coleta de dados em alguns aspectos, mas que são tentativas de construir um conhecimento sobre tais representações mentais. Quanto ao desenho da família, mesmo com desenhos sem muita clareza devido a motricidade fina pouco desenvolvida, foi possível observar ansiedade, insegurança e representações negativas de maneira geral na execução dos desenhos, que reforçam os dados coletados nos demais instrumentos.

Compreender as representações associadas às figuras parentais são ações importantes para o processo terapêutico e possíveis mudanças futuras, pois quando há uma compreensão mais fidedigna das conflitivas dessas crianças, especificadamente, pode-se facilitar a criação de intervenções mais adequadas, bem como possibilidade de ações, em políticas públicas, que visem à prevenção ou agravamento de patologias associadas às representações parentais negativas, institucionalização e às implicações do uso do crack pelos pais. Destaca-se também a possibilidade de capacitar os profissionais que trabalham diretamente com crianças nessas situações, pois tais crianças precisam de um olhar diferenciado às demandas de ansiedade, agitação e demais consequências da fragilização do vínculo e do afastamento do convívio familiar. Certamente esse 
estudo não saturou as possibilidades de aprofundamento da temática, dessa forma evidencia-se a continuidade de novos estudos acerca das figuras parentais nesse contexto, por exemplo, um estudo com caráter longitudinal. Pois somente a partir do sólido conhecimento é possível explanar e elaborar ações que deem conta das demandas, prevalecendo a qualidade do atendimento.

\section{Referências}

Achenbach, T. M. (1991). Manual for child behavior checklist/ 4-18 and 1991 profile. Department of Psyquiatry. University of Vermont.

Alcioli Neto, M. L. (2014). Os contextos de uso do crack: representações e práticas sociais entre usuários. Dissertação apresentada ao Programa de Pós-Graduação de Psicologia da Universidade Federal de Pernambuco, como requisito parcial à obtenção do grau de Mestre em Psicologia. Orientação: Prof. a Dra. Maria de Fátima de Souza Santos.

Alves, H. N. P.; Ribeiro, M.; Castro, D. S. de. (2011). Cocaína e Crack. In: Diehl, A.; Cordeiro, D. C.; Laranjeira, R e col. Dependência química: prevenção, tratamento e políticas públicas. Porto Alegre: Artmed.

Andrade, T. M. de. (2011). Reflexões sobre Políticas de Drogas no Brasil. Bahia: Ciência e Saúde Coletiva, (16)12. Retrieved from http://www.scielo.br/pdf/csc/v16n12/15.pdf

Azôr A. M. G. C. C. V. \& Vectore, C. (2008). Abrigar/desabrigar: conhecendo o papel das famílias nesse processo. Campinas: Estudos de Psicologia, 25(1), 77-89. doi: 10.1590/S0103$166 \times 2008000100008$

Barbosa, K. K. S. et al. (2015). Concepções de usuários de crack acerca da droga. Revista de Enfermagem UFSM, 5(2): 286-294. doi: $10.5902 / 2179769213474$

Bauer, C. R.; Langer, J. C.; Shankaran, S.; Bada, H. S.; Lester, B.; Wright, L. L.; Krauser-Steinrauf, H.; Smeriglio, V. F.; Finnegen, L. P.; Maza, P. L.; Verter, J. (2005). Acute neonatal effects of cocaine exposure during pregnancy. Arch Pediatry Adolesc Med, 159(9). doi: 10.1001/archpedi.159.9.824

Bleichmar, N. M. \& Bleichmar, C. L. (1992). A psicanálise depois de Freud: teoria e clínica. Porto Alegre: Artes Médicas.

Bordin, I. A. S; Mari, J. J; Caiero, M. F. (1995). Validação da versão brasileira do "Child Behavior Checklist": dados preliminares. Revista Brasileira de Psiquiatria (17)2, 55-66.

Bordin, S.; Figlie, N. B.; Laranjeira, R. (2010). Cocaína e Crack. In: Figlie, N. B.; Bordin, S.; Laranjeira, R. Aconselhamento em dependência química. FIGLIE, N. B. (org.), São Paulo: Roca. 
Borsa, J. C. \& Nunes, M. L. T. (2008). Concordância parental sobre problemas de comportamento infantil através do CBCL. Paidéia, 18(40). doi: 10.1590/S0103-863X2008000200009

Botti, N. C. L.; Costa, B. T.; Henriques, A. P. F. (2011). Composição e dinâmica das famílias uruárias de crack. Florianópolis: Cadernos Brasileiros de Saúde Mental, (3)7, 93-110. Retrieved from http://incubadora. periodicos.ufsc.br/index.php/cbsm/article/vie w/1907/2181

Bowlby, J. (1981). Cuidados maternos e saúde mental. São Paulo: Martins Fontes.

Bowlby, J. (1984). Apego e perda: Vol. 2. Separação: angústia e raiva. São Paulo: Martins Fontes.

Bowlby, J. (2006). Formação e rompimento dos laços afetivos. São Paulo: Martins Fontes.

Brasil (1999). Estatuto da criança e do adolescente (ECA). Diário Oficial da União. Lei no 8069, de 13 de julho de 1990. Brasília, DF.

Brasil (2006). Ministério do Desenvolvimento Social e Combate à Fome. Secretaria Especial dos Direitos Humanos. Plano nacional de promoção, proteção e defesa do direito de crianças e adolescentes à convivência familiar e comunitária. Brasília, DF: CONANDA/CNAS.

Brasil. (2009). Código civil. In: Pinto, A. L. T.; Windt, M. C. V. S.; Céspedes, L. (Colab.). Vade mecum. 8. ed. atual. e ampl. São Paulo: Saraiva.

Bronfenbrenner, U. (1996). A ecologia do desenvolvimento humano: Experimentos naturais e planejados. Porto Alegre: Artes Médicas.

Buck, J. (2009). H-T-P: casa-árvore-pessoa, técnica projetiva de desenho: guia de interpretação. Trad. Renato Cury Tardivo; Revisão Irai Cristina Boccato Alves. São Paulo: Vetor.

Camargo, P. de O. \& Martins, M. de F. D. (2012). Mitos e verdades sobre os efeitos do crack nos bebês nascidos de mães usuárias: uma revisão bibliográfica. Pelotas: XIV Encontro de PósGraduação realizado pela Universidade Federal de Pelotas.

Capisano, H. F. (2010). Imagem corporal. In: Mello Filho, J.; Burd, M. Psicossomática hoje. São Paulo: Casa do Psicólogo.

Cavalcante, L. I. C.; Silva, S. S. da C.; Magalhães, C. M. C. (2010). Institucionalização e reinserção familiar de crianças e adolescentes. Fortaleza: Revista Mal-Estar e Subjetividade, 10(4), 1147-1172.

CNJ (Conselho Nacional de Justiça) (2011). Cartilha sobre o crack. Conselho Nacional do Ministério Público, 4 ed. Retrieved from http://www.tjdft.jus.br/publicacoes/manuais-ecartilhas/cartilha_crack.pdf 
Corman, L. (1979). O teste do desenho de família. Trad. Walter H. Geenen. São Paulo: Mestre Jou.

Corso, D. L. \& Corso, M. (2006). Fadas no divã: Psicanálise nas histórias infantis. Porto Alegre: Artmed.

Covington, C. Y.; Nordstrom-Klee, B.; Ager, J. Sokol, R.; DelaneyBlack, V. (2002). Birth to age 7 growth of children prenatally exposed to drugs: a prospective cohort study. Neurotoxicol Teratol, 24(4). doi: 10.1016/S0892-0362(02)00233-7

Creswell, J. W. (2010). Projeto de Pesquisa: métodos qualitativos, quantitativos e misto. São Paulo: Artmed.

Custódio, S. \& Cruz, O. (2008). As representações mentais das crianças acerca das figuras parentais. Psicologia e Pesquisa, 24(4). doi: 10.1590/S0102-37722008000400002

Emde, R.; Wolf, D.; Oppenheim, D. (2003). Revealing the Inner Worlds of Young Children: The MacArthur story Stem Battery and Parent-Child Narratives. New York: Oxford University Press.

Espíndola, D. H. P. et al. (2015). Representações sociais de crack e adolescência na imprensa pernambucana. Temas psicológicos, 23(2), Ribeirão Preto. doi: 10.9788/TP2015.2-04

Fante, A. P. \& Cassab, L. A. (2007). Convivência familiar: um direito à criança e ao adolescente institucionalizado. Porto Alegre: Revista Textos \& Contextos, (6)1, 154-174.

Ferreira, L. \& Bittencourt, S. (2009). Direito à convivência familiar de crianças abrigadas: o papel do Ministério Público. Revista Em Pauta da Faculdade de Serviço social da Universidade do Estado do Rio de Janeiro, (6)23. Retrieved from http://www.epublicacoes.uerj.br/index.php/revistaempauta/article/viewFile/4 $51 / 549$

FPE. (2014). Levantamento da população acolhida elaborada pelo Núcleo de Monitoramento, Avaliação e Pesquisa da FPE - CAE $D T$. Porto Alegre.

Giacomello, K. J. \& Melo, L. de L. (2011). Do faz de conta à realidade: compreendendo $o$ brincar de crianças institucionalizadas vítimas de violência por meio do brinquedo terapêutico. Campinas: Ciência \& Saúde Coletiva, (16)1, 15711780.

Grych, J. H.; Wachmuth-Schlaefer, T.; Klockow, L. L. (2002). Interparental aggression and young children's representations of family relationships. Journal of family psychology, (16)3. doi: $0.1037 / / 0893-3200.16 .3 .259$

ICF International. (2009). Child abuse and neglect user manual series: Protecting Children in Families Affected by Substance Use Disorders. USA: Departamento of Healthy and Human Services.

INPAD (Instituto Nacional de Ciência e Tecnologia para Políticas Públicas do Álcool e outras Drogas). (2013). II Levantamento 
Nacional de Álcool e Drogas (II LENAD). Brasil, 2013. Retrieved from http://inpad.org.br/lenad/cocaina-e-crack/resultadospreliminares/

Kessler, F. \& Pechansky, F. (2008). Uma visão psiquiátrica sobre o fenômeno do crack na atualidade. Porto Alegre: Rev. Psiquiatria RS, (30)2. doi: 10.1590/S0101-81082008000300003

Marques, A. C. P. R.; Ribeiro, M.; Laranjeira, R. R.; Andrada, N. C. de. (2012). Abuso e dependência: crack. Rev. Assoc. Med. Bra., (58)2. Retrieved from http://www.scielo.br/pdf/ramb/v58n2/v58n2a08.pdf

Mcarthur, M.; Moore, T.; Noble-Carr, D. (2010). Who cares? Young people who use alcohol or other drugs talk about their experiences with services. Austrália: Family Matters.

Mendes, T. C. \& Sani, A. (2015). Representações de crianças expostas à violência interparental através de provas projetivas. Journal of Child and Adolescent Psychology, Revista de Psicologia da Criança e do Adolescente. Lisboa, 6(1). Retrieved from:

http://revistas.lis.ulusiada.pt/index.php/rpca/article/view/1979/ 2096

Moreira, M. M. \& Mitsuhiro, S. S.; Ribeiro, M. (2012). O consumo de crack durante a gestação. In: Ribeiro, M. \& Laranjeira, R. (org.). O tratamento do usuário de crack. Porto Alegre: Artmed.

Nascimento, M. L. de; Lacaz, A. S.; Travassos, M. (2010). Descompassos entre a lei e o cotidiano do abrigo: percursos do ECA. Aletheia, 31, 16-25. Retrieved from http://pepsic.bvsalud.org/scielo.php?pid=S141303942010000100003\&script=sci_arttext

Payá, R. \& Figlie, N. B. (2010). Filhos de Dependentes Químicos. In: Figlie, N. B.; Bordin, S.; Laranjeira, R. Aconselhamento em dependência química. Figlie, N. B. (org.), São Paulo: Roca.

Pereira, J. C. R. (1999). Análise de dados qualitativos: Estratégias Metodológicas para as Ciências da Saúde, Humanas e Sociais. São Paulo: Editora da Universidade de São Paulo, 2. Ed.

Perreira, T. da S. (2004). Famílias possíveis: novos paradigmas na convivência familiar. In: Perreira, R. da C. (coord.). Afeto, ética, família e o novo Código Civil - Anais do IV Congresso Brasileiro de Direito de Família. Belo Horizonte: Del Rey, p. 633-656.

Perrenoud, L. O. \& Ribeiro, M. (2012). Histórico do consumo de crack no Brasil e no mundo. In: Ribeiro, M. \& Laranjeira, R. (org.). $O$ tratamento do usuário de crack. Porto Alegre: Artmed.

Pettenon, M. \& Diemen, L. V. (2010). Uso de substâncias psicoativas e violência. Revista Brasileira de Psicoterapia, (12). Retrieved from http://rbp.celg.org.br/detalhe_artigo.asp?id=35

Pinhel, J.; Torres, N.; Maia, J. (2009). Crianças institucionalizadas e crianças em meio familiar de vida: representaçőes de 
vinculação e problemas de comportamento associado. Análise Psicológica, (27)4, 509-521. Retrieved from http://hdl.handle.net/10400.12/255

Pinho, L. B. de; Oliveira, I, R.; Gonzales, R. I. C.; Harter, J. (2012). Consumo de crack: repercusiones en la estructura y en la dinámica de las relaciones familiares. Revista electrónica trimestral de Enfermería, 25. doi: 10.4321/S169561412012000100009

Prada C. G. \& Weber, L. N. D. (2006). O abrigo: análise de relatos de crianças vítimas de violência doméstica que vivem em instituições. São Paulo: Revista de Psicologia da UNESP, (5)1. Retrieved from http://www2.assis.unesp.br/revpsico/index.php/revista/article/ viewFile/33/63

Prada, C. G.; Williams, L. C. de A.; Weber, L. N. D. (2007). Abrigos para crianças vítimas de violência doméstica: funcionamento relatado pelas crianças e pelos dirigentes. Psicologia: Teoria e Prática, (9)2, 14-25. Retrieved from http://www.nac.ufpr.br/artigos_do_site/2007_Abrigos_para_cri ancas_vitimas_de_violencia_domestica.pdf

Rabello, N. (2013). O desenho infantil: entenda como a criança se comunica por meio de traços e cores. Rio de Janeiro: Wak Editora.

Relatório da Infância e Juventude - Resolução no 71/2011. (2013). Um olhar mais atento aos serviços de acolhimento de crianças e adolescentes no País. Brasília: Conselho Nacional do Ministério Público. Retrieved from http://www.cnmp.mp.br/portal/images/stories/Destaques/Publi cacoes/Res_71_VOLUME_1_WEB_.PDF

Ribeiro, M.; Nudelman, E. D.; Rezende, E. P.; Yamauchi, R. (2012). Farmacologia do consumo de crack. In: Ribeiro, M. \& Laranjeira, R. (org.). O tratamento do usuário de crack. Porto Alegre: Artmed.

Robinson, J.; Mantz-Simmons, L.; Macfie, J.; Kelsay, K.; Holmberg, J. (2007). MacArthur Narrative Conding Manual. Unplublished manuscript.

Silva, E. R. A. da. (2004). O perfil da criança e do adolescente nos abrigos pesquisados. In: Silva, E. R. A. da. O direito à convivência familiar e comunitária: os abrigos para crianças e adolescentes no Brasil. IPEA/DISOC. Levantamento Nacional de Abrigos para Crianças e Adolescentes da Rede SAC. Relatório de Pesquisa número 1. Brasília, outubro de 2003 (não publicado). Conanda, Brasília, cap. 2.

Silva, E. R. A. da; Mello, S. G. de; Aquino, L. M. C. de. (2004). Os abrigos para crianças e adolescentes e a promoção do direito à convivência familiar e comunitária. In: Silva, E. R. A. da. O 
direito à convivência familiar e comunitária: os abrigos para crianças e adolescentes no Brasil. IPEA/DISOC. Levantamento Nacional de Abrigos para Crianças e Adolescentes da Rede SAC. Relatório de Pesquisa número 1. Brasília, outubro de 2003 (não publicado). Conanda, Brasília, cap. 8.

Siqueira, A. C. \& Dell'aglio, D. D. (2006). O impacto da institucionalização na infância e na adolescência: uma revisão de literatura. Psicologia \& Sociedade, (18)1, 71-80. doi: 10.1590/S0102-71822006000100010

Siqueira, A. C.; Tubino, C. de L.; Schwarz, C.; Dell'aglio, D. D. (2009). Percepções das figuras parentais na rede de apoio de crianças e adolescentes institucionalizados. Arquivos Brasileiros de Psicologia, (61)1. Retrieved from http://pepsic.bvsalud.org/scielo.php?script=sci_arttext\&pid=S1 809-52672009000100017

Souza, M. \& Cruz, O. M. (2010). As narrativas das crianças institucionalizadas: a experiência de maus-tratos e a construção de modelos representacionais. In: VII Simpósio Nacional de Investigação em Psicologia, Portugal: Universidade do Minho. Retrieved from http://sigarra.up.pt/fpceup/pt/publs_pesquisa.show_publ_file?p ct_gdoc_id=7173

Souza, M. L. (2015). As representações sociais de crianças em acolhimento institucional: Proteção ou Revitimização? Dissertação apresentada à Faculdade de Ciências Humanas e Sociais, da Universidade Estadual Paulista "Júlio de Mesquita Filho", como pré-requisito para obtenção do Título de Mestre em Serviço Social. Área de Concentração: Serviço Social: formação e prática profissional. Orientadora: Profa. Dra. Djanira Soares de Oliveira e Almeida.

Vectore, C., Carvalho, C. (2008). Um olhar sobre o abrigamento: a importância dos vínculos em contexto de abrigo. Revista Semestral da Associação Brasileira de Psicologia Escolar e Educacional (ABRAPEE), (12)2, 441-449. doi: 10.1590/S141385572008000200015

Winnicott, D. W. (1975). O brincar e a realidade. Rio de janeiro: Imago.

Winnicott, D. W. (1988). A dependência nos cuidados infantis. In: Winnicott, D. W. Os bebês e suas mães. São Paulo: Martins Fontes.

Winnicott, D. W. (2000). Da Pediatria à Psicanálise: obras escolhidas. Rio de Janeiro: Imago. 


\section{Endereço para correspondência}

\section{Luciane Maria Both}

Universidade do Vale do Rio dos Sinos - UNISINOS

Av. Unisinos, 150, CEP 93022-000, São Leopoldo - RS, Brasil

Endereço eletrônico: lucianeboth@gmail.com

\section{Sílvia Pereira da Cruz Benetti}

Universidade do Vale do Rio dos Sinos - UNISINOS

Av. Unisinos, 150, CEP 93022-000, São Leopoldo - RS, Brasil

Endereço eletrônico: spcbenetti@gmail.com

Recebido em: 06/12/2015

Reformulado em: 31/10/2016

Aceito em: 16/11/2016

\section{Notas}

* Psicóloga, Mestra em Psicologia Clínica.

** Psicóloga, Doutora em Psicologia, Professora na Universidade do Vale do Rio dos Sinos (UNISINOS).

${ }^{1}$ Nomes fictícios.

${ }^{2}$ Nomes fictícios.

${ }^{3}$ Ocorrência de denúncia ao Conselho Tutelar.

${ }^{4}$ Nos itens nos quais não há codificação, sua avaliação feita através da ausência ou presença dos itens.

\section{Anexos}

Tabela 1

Narrativas do MSSB

\begin{tabular}{|c|c|c|}
\hline História & Conteúdo & Temática Predominante \\
\hline $\begin{array}{l}\text { História Introdutória: } \\
\text { o aniversário de Jorge } \\
\text { e Suzana. }\end{array}$ & $\begin{array}{l}\text { Comemoração do aniversário } \\
\text { de Jorge e Suzana. }\end{array}$ & $\begin{array}{l}\text { Introdução, modelando as } \\
\text { narraçōes com as figuras } \\
\text { da familia. }\end{array}$ \\
\hline $\begin{array}{l}\text { História 1: Suco } \\
\text { derramado. }\end{array}$ & $\begin{array}{l}\text { Jorge derruba o copo de suco } \\
\text { no chäo durante a refeição. }\end{array}$ & $\begin{array}{l}\text { Resposta parental do } \\
\text { acidente } \\
\text { autoridade). }\end{array}$ \\
\hline $\begin{array}{l}\text { História 2: Procurando } \\
\text { Bobi. }\end{array}$ & $\begin{array}{l}\text { o cachorro Bobi fugiu de } \\
\text { casa, em seguida, há o } \\
\text { reencontro. }\end{array}$ & Perda e reunião (afeto). \\
\hline $\begin{array}{l}\text { História 3: A mãe com } \\
\text { dor de cabeça. }\end{array}$ & $\begin{array}{l}\text { Mãe com dor de cabeça } \\
\text { solicita silencio, mas amigo } \\
\text { de Jorge chega propondo } \\
\text { assistir um filme na sua casa. }\end{array}$ & $\begin{array}{l}\text { Dilema sobre a empatia } \\
\text { com a mäe versus a } \\
\text { lealdade ao amigo (dilema } \\
\text { moral). }\end{array}$ \\
\hline $\begin{array}{l}\text { História 4: Presente } \\
\text { para mamãe e papai. }\end{array}$ & $\begin{array}{l}\text { Suzana realizou um lindo } \\
\text { desenho na escola e na volta } \\
\text { pra casa da o trabalho aos } \\
\text { pais. }\end{array}$ & $\begin{array}{l}\text { Preferência por um dos } \\
\text { pais (conflito edípico). }\end{array}$ \\
\hline $\begin{array}{l}\text { História 5: Três são } \\
\text { muitos: o conto. }\end{array}$ & $\begin{array}{l}\text { Suzana está sentada no colo } \\
\text { do pai ouvindo uma história, } \\
\text { porém Jorge interrompe } \\
\text { solicitando que ele também }\end{array}$ & $\begin{array}{l}\text { Dilema de lealdade ao } \\
\text { amigo versus empatia } \\
\text { com o irmão (conflito de } \\
\text { pares). }\end{array}$ \\
\hline
\end{tabular}




\begin{tabular}{|c|c|c|}
\hline História & Conteúdo & Temática Predominante \\
\hline $\begin{array}{l}\text { História } 6: \text { Molho } \\
\text { quente. }\end{array}$ & $\begin{array}{l}\text { Mãe está cozinhando o jantar } \\
\text { e Jorge não quer esperar. Ele } \\
\text { derrama a panela no chão e } \\
\text { queima o dedo. }\end{array}$ & $\begin{array}{l}\text { Desobediência, empatia } \\
\text { parental versus autoridade } \\
\text { (afeto e autoridade). }\end{array}$ \\
\hline $\begin{array}{l}\text { História 7: Chaves } \\
\text { perdidas. }\end{array}$ & $\begin{array}{l}\text { Mãe acusa o pai de este ter } \\
\text { roubado as suas chaves. }\end{array}$ & $\begin{array}{l}\text { Conflito parental (conflito } \\
\text { familiar). }\end{array}$ \\
\hline $\begin{array}{l}\text { Historia 8: Roubando } \\
\text { a loja de doces. }\end{array}$ & $\begin{array}{l}\text { Jorge quer um doce, porem } \\
\text { mãe não satisfaz, dessa } \\
\text { forma ele pega escondido, } \\
\text { mas é flagrado pelo guarda } \\
\text { da loja. }\end{array}$ & $\begin{array}{l}\text { Transgressäo, ser pego, } \\
\text { vergonha (moral). }\end{array}$ \\
\hline História 9: Despedida & $\begin{array}{l}\text { Pais vão viajar saem de } \\
\text { viagem durante dois dias } \\
\text { enquanto filhos permanecem } \\
\text { com avó. Após, há o retorno } \\
\text { dos pais para casa. }\end{array}$ & Perda e reunião (afeto). \\
\hline $\begin{array}{l}\text { História 10: A estante } \\
\text { do banheiro }\end{array}$ & $\begin{array}{l}\text { As crianças foram impedidas } \\
\text { de mexer na estante do } \\
\text { banheiro, local onde se } \\
\text { guarda os curativos, pois foi } \\
\text { consertada. Durante o tempo } \\
\text { que a mãe foi no vizinho, } \\
\text { Suzana corta o dedo. Após, } \\
\text { há o retorno da mãe. }\end{array}$ & $\begin{array}{l}\text { Dilema sobre obediência a } \\
\text { mãe versus empatia com } \\
\text { o irmão (dilema moral). }\end{array}$ \\
\hline $\begin{array}{l}\text { História 11: Excursão } \\
\text { ao parque. }\end{array}$ & $\begin{array}{l}\text { Familia vai ao parque e Jorge } \\
\text { deseja escalar uma pedra. } \\
\text { Mãe pede para ele tomar } \\
\text { cuidado. }\end{array}$ & $\begin{array}{l}\text { Dominio/orgulho (domínio } \\
\text { e afeto). }\end{array}$ \\
\hline História 12: Exclusão. & $\begin{array}{l}\text { Pais estão na sala } \\
\text { conversando e solicitam aos } \\
\text { filhos irem para os seus } \\
\text { quartos. }\end{array}$ & $\begin{array}{lr}\text { Exclusão } & \text { do } \\
\text { relacionamento } & \text { parental } \\
\text { (tema edipiano). } & \end{array}$ \\
\hline $\begin{array}{l}\text { História 13: O pote de } \\
\text { biscoitos. }\end{array}$ & $\begin{array}{l}\text { Suzana pega um biscoito do } \\
\text { pote da cozinha e jorge alerta } \\
\text { que ela não poderia. Os pais } \\
\text { estão chegando à cozinha. }\end{array}$ & $\begin{array}{l}\text { Conflito entre lealdade aos } \\
\text { pais e lealdado ao irmão } \\
\text { (dilema moral). }\end{array}$ \\
\hline $\begin{array}{l}\text { História final: Diversão } \\
\text { em familia. }\end{array}$ & $\begin{array}{l}\text { Está toda familia reunida em } \\
\text { casa para realizar atividades } \\
\text { que as crianças desejam. }\end{array}$ & Diversão familiar. \\
\hline
\end{tabular}

\section{Macarthur narrative coding manual ${ }^{4}$}

Tabela 2

Material de correção das narrativas do MSSB

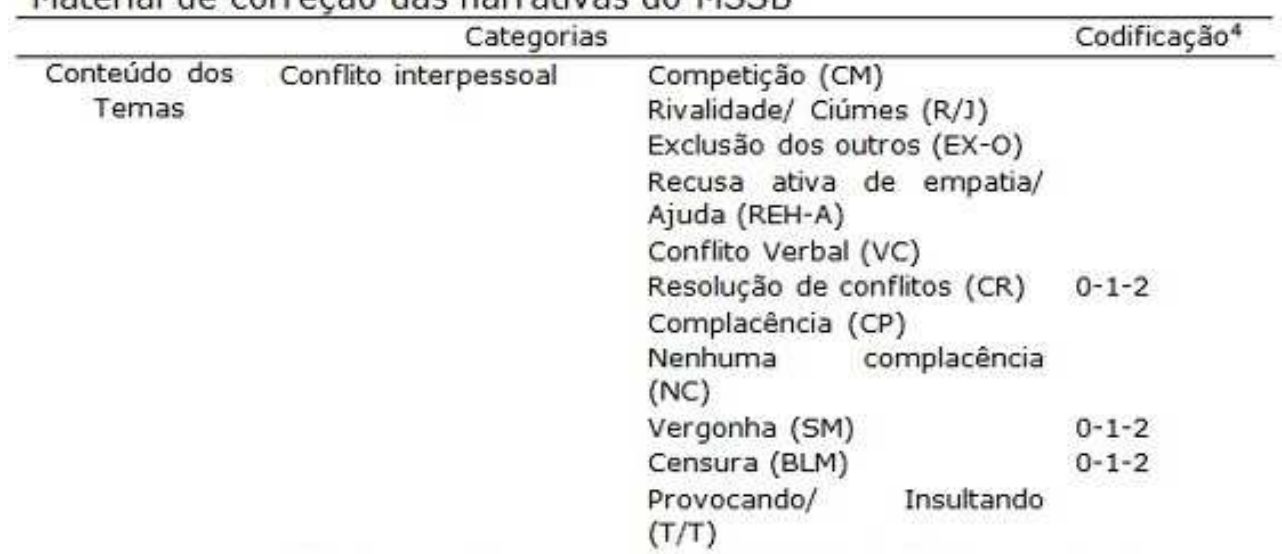




\begin{tabular}{|c|c|c|c|}
\hline \multicolumn{3}{|c|}{ Categorias } & \multirow{2}{*}{$\frac{\text { Codificação }}{0-1-2}$} \\
\hline Conteúdo dos & Relação empática & Partilha/ Dividindo (SH) & \\
\hline \multirow[t]{12}{*}{ Temas } & & $\begin{array}{l}\text { Empatia/ Ajuda/ Confiança } \\
(E / H)\end{array}$ & $0-1-2$ \\
\hline & & Afiliação/ Associação (AFL) & $0-1-2$ \\
\hline & & Afeto (AFF) & $0-1-2$ \\
\hline & & Reparação/ Culpa (RG) & $0-1-2$ \\
\hline & Agressão desregulada & Agressão (AGG) & 0 aо 5 \\
\hline & & $\begin{array}{l}\text { Agravamento do conflito } \\
\text { interpessoal (ESC) }\end{array}$ & \\
\hline & & Dano/ Ofensa pessoal (PI) & \\
\hline & & Respostas atipicas (AR) & $0-1-2$ \\
\hline & & $\begin{array}{ll}\text { Atividade/ } & \text { Agressão } \\
\text { sexualizada } & \end{array}$ & \\
\hline & Temas Morais & Desonestidade (DSH) & \\
\hline & & $\begin{array}{l}\text { Punição/ } \\
\text { Disciplina/Maturidade (PD) }\end{array}$ & $0-1-2$ \\
\hline & & Educação/ Polidez (POL) & \\
\hline \multirow{12}{*}{$\begin{array}{l}\text { Códigos } \\
\text { emocionais das } \\
\text { Narrativas }\end{array}$} & Tema de perigo (DAN) & & $0-1-2-3$ \\
\hline & Segurança (SAF) & & \\
\hline & $\begin{array}{l}\text { Destruição dos objetos } \\
\text { (DES) }\end{array}$ & & $0-1-2$ \\
\hline & Poder da Criança (POW) & & $0-1-2$ \\
\hline & $\begin{array}{l}\text { Reaçäo de separaçăo } \\
\text { (SEP) }\end{array}$ & & $0-1-2$ \\
\hline & Esperança & & \\
\hline & Incoerência Emocional & & \\
\hline & Positiva (INCPO) & & \\
\hline & Incoerência Emocional & & \\
\hline & Negativa (INCNEG) & & \\
\hline & Primeira Reação (FIR) & & $0-1-2$ \\
\hline & Conteúdo Final (FIN) & & $0-1-2$ \\
\hline \multirow[t]{8}{*}{$\begin{array}{l}\text { Representaçб̌es } \\
\text { parentais }\end{array}$} & Positiva (POS) & $\begin{array}{l}\text { Protetor } \\
\text { Afetuoso }\end{array}$ & \\
\hline & & Cuidador & \\
\hline & & Ajuda & \\
\hline & Negativa (NEG) & Punitivas & \\
\hline & & Rejeição & \\
\hline & & Ineficaz & \\
\hline & $\begin{array}{l}\text { Disciplina/Controle } \\
(\mathrm{D} / \mathrm{C})\end{array}$ & & \\
\hline & Triangulação (TTR) & & $0-1-2$ \\
\hline \multirow{15}{*}{$\begin{array}{l}\text { Códigos de } \\
\text { performance }\end{array}$} & Controle (CRT) & & $0-1$ \\
\hline & Alegria & & $0-1-2$ \\
\hline & Raiva & & $0-1-2$ \\
\hline & Angústia & & $0-1-2$ \\
\hline & Interesse & & $0-1-2$ \\
\hline & Tristeza & & $0-1-2$ \\
\hline & Comportamento ansioso & & $0-1-2$ \\
\hline & Reflexão & & $0-1-2$ \\
\hline & $\begin{array}{l}\text { Criatividade/ } \\
\text { Imaginação }\end{array}$ & & \\
\hline & $\begin{array}{l}\text { Estilo de performance } \\
\text { direto/ indireto }\end{array}$ & & $0-1-2$ \\
\hline & Papel dos pais & & $0-1-2-3$ \\
\hline & Coerência narrativa & & 0 a 10 \\
\hline & Responsabilidade & & $1-2-3$ \\
\hline & $\begin{array}{l}\text { criança com } \quad 0 \\
\text { examinador }\end{array}$ & & \\
\hline & Pedido para parar & & \\
\hline \multirow[t]{7}{*}{$\begin{array}{l}\text { Estratégias de } \\
\text { Evitaçăo }\end{array}$} & $\begin{array}{l}\text { Exclusão de si mesmo } \\
\text { (EX-S) }\end{array}$ & & \\
\hline & Repetição (REP) & & $0-1-2-3$ \\
\hline & Negação (DNL) & & $0-1-2$ \\
\hline & $\begin{array}{l}\text { Recusa de empatia/ } \\
\text { ajuda passiva (REH-P) } \\
\text { Sono repentino (SSO) }\end{array}$ & & \\
\hline & Brincar fora do assunto & & $0-1-2$ \\
\hline & $\begin{array}{l}\text { Ruptura tamiliar } \\
\text { Corrigindo/Revisando }\end{array}$ & & \\
\hline & Objetivos Bloqueados & & \\
\hline
\end{tabular}


Luciane Maria Both, Sílvia Pereira da Cruz Benetti

\begin{tabular}{|c|c|c|c|}
\hline \multicolumn{3}{|r|}{ Categorias } & Codificação \\
\hline \multirow[t]{5}{*}{$\begin{array}{l}\text { Códigos de } \\
\text { dissociação }\end{array}$} & $\begin{array}{l}\text { Material } \\
\text { (ITM) }\end{array}$ & Traumático & \\
\hline & $\begin{array}{l}\text { Propensäo à } \\
\text { (FP) }\end{array}$ & fantasia & \\
\hline & Distração (SO) & & \\
\hline & $\begin{array}{l}\text { Fuga do } \\
\text { doloroso (FSP) }\end{array}$ & assunto & \\
\hline & $\begin{array}{l}\text { Identificação } \\
\text { agressor (IWA) }\end{array}$ & com 0 & \\
\hline
\end{tabular}

